\title{
Spatial Distribution and Factors Associated with Risky Health Behaviour Among Adult Males Aged 15-59 Years in Ethiopia; Generalized Structural Equation Modelling
}

Sewnet Adem Kebede ( $\nabla$ sewnetme1@gmail.com )

University of Gondar College of Medicine and Health Sciences https://orcid.org/0000-0001-7750-7596

Adisu Birhanu Weldesenbet

Haramaya University College of Health and Medical Sciences

Biruk Shalmeno Tusa

Haramaya University College of Health and Medical Sciences

Research article

Keywords: Risky health behaviour, spatial analysis, generalized structural equation modelling, Ethiopia

Posted Date: August 21st, 2020

DOI: https://doi.org/10.21203/rs.3.rs-54733/v1

License: (9) (1) This work is licensed under a Creative Commons Attribution 4.0 International License. Read Full License 


\section{Abstract}

Background: Alcohol drinking and tobacco smoking are the largest preventable cause of death and important risk factors for a number of non-communicable diseases and cause premature death and many socioeconomic consequences. Therefore, the present study aimed to assess the spatial distribution of risky health behaviour and its associated factors among adult males in Ethiopia.

Methods: Secondary data analysis was conducted among 12,688 men (aged 15-59 years). The distribution of risky health behaviour across the country was observed by ArcGIS software. In SaTScan software, the Bernoulli model was fitted by Kulldorff methods to identify the purely spatial clusters of risky health behaviour. Generalized Structural Equation Model (GSEM) was used to determine factors associated with each domain of risky health behaviour (regular alcohol drinking and tobacco smoking).

Results: Risky health behaviour had spatial variation across the country. The primary clusters were located in Tigray, Amhara and north-eastern Benishangul national regional states. Spatial scan statistics identified 118 primary clusters (LogLikelihood ratio $(L L R)=524.8, p<0.001)$. Residence, frequency of listening to a radio, occupation and frequency of watching television were significantly associated with drinking alcohol whereas wealth index was associated with tobacco smoking. Age, region, educational status, marital status and religion had association with both domains of risky health behaviour.

Conclusion: Risky health behaviour had spatial variation across the country. The national press media in ban of advertising and promotion of alcohol and tobacco should be strengthen. Aggressive health education efforts should be directed toward this high-risk population (Tigray, Amhara and north-eastern Benishangul regional states). Improving risky health behaviour is an important approach to reducing health disparities and for more cost-effective utilization of scarce resources in the public health sector.

\section{Background}

Risky health behaviour can be defined as an activity performed by people with a frequently or intensity that increases the risk of disease or injury now or in the future $(1,2)$. Risky health behaviours include physical inactivity, unhealthy diet, tobacco use, drug abuse ,unprotected sexual practices and harmful use of alcohol (3).

Tobacco use and alcohol drinking poses a serious challenge to ongoing efforts to prevent non-communicable diseases (NCD) including cancer, diabetes, cardiovascular disease and chronic obstructive pulmonary disease (COPD), which account for over $80 \%$ of all premature NCD deaths globally (4-6). Children, adults and the elderly are all vulnerable to the risk factors contributing to NCDs, whether from unhealthy diets, physical inactivity, exposure to tobacco smoke or the harmful use of alcohol (7).

Risky health behaviour affect both sustainable development goals (SDG) related to health (SDGs $1,2,4,5, \& 6)$ and SDGs outside the health sector (SDGs $8,10,11,14,15,16 \& 17$ ) and more directly related to SDG3 (8). It has a direct impact on many health-related targets of the Sustainable Development Goals (SDGs) specifically mentioned under SDG 3, including those for maternal and child health, infectious diseases (HIV, viral hepatitis, tuberculosis), NCD, mental health, injuries and poisonings. Alcohol drinking and tobacco smoking specifically mentioned under health Target 3.5: "Strengthen the prevention and treatment of substance use, including narcotic drug abuse and harmful use of alcohol" $(5,8)$.

In 2016, the harmful use of alcohol resulted in some 3 million deaths (5.3\% of all deaths) worldwide. Mortality resulting from alcohol consumption is higher than that caused by diseases such as tuberculosis, HIV/AIDS and diabetes. Worldwide, alcohol was responsible for $7.2 \%$ (among persons 69 years of age and younger) of all premature mortality in $2016(5,7,9)$. Recent World Health Organization (WHO) estimates indicate that about 1.1 billion people use tobacco worldwide. Tobacco use is responsible for over 7 million deaths annually, with over $80 \%$ of deaths occurring in low and mid-income countries (10). 
The WHO global report on trends in the prevalence of tobacco smoking showed that the prevalence of tobacco smoking appears to be declining in almost all regions of the world, with the exception of the African and Eastern Mediterranean regions, where the trends are flat (11). The burden of tobacco-related deaths in Africa increased from 150,000 reported deaths in 1990 to over 215,000 in 2016, representing about $70 \%$ increase in mortality. The highest number of deaths was recorded in Eastern Africa while the lowest was recorded in Central Africa (12). Although the highest levels of alcohol consumption are in Europe, Africa bears the heaviest burden of disease and injury attributed to alcohol (5). The alcohol attributable burden of disease was higher among men than among women (13).

Alcohol and tobacco use among adult men in Ethiopia was $46.6 \%$ and $7.3 \%$ in 2015 respectively (14). Even though fewer men die from tobacco in Ethiopia than the average in countries with low human development index, tobacco kills 258 men every week (15). Tobacco use directly fuels poverty. It drives resources from other basic needs such as nutrition, education and health (8). The economic cost of smoking in Ethiopia amounts to 1391 million Ethiopian birr (ETB). This includes direct costs related to healthcare expenditures and indirect costs related to lost productivity due to early mortality and morbidity (15).

Different studies were conducted in different part of Ethiopia using a univariate analysis to determine factors associated with risky health behaviour (16-19). In this analysis only one dependent variable is allowed. However, risky health behaviour has two domains (alcohol drinking and tobacco smoking) which need to be considered as independent variables.

Furthermore, the prevalence of risky health behaviour is not geographically homogenous.

Therefore, the present study applies spatial analysis to identify geographic distribution of risky health behaviour and generalized structural equation model (GSEM) to determine factors associated with two domains of risky health behaviour. Understanding the spatial distribution of alcohol drinking and tobacco smoking, along with the factors contributing to their use, is crucial for developing targeted tobacco and alcohol control policies and reducing alcohol and tobacco related harm.

Figure 1: Hypothesized model for factors associated with risky health behaviour among males in Ethiopia.

\section{Method}

\section{Study design, period and setting}

Community-based cross-sectional study was conducted in Ethiopia from January 18 to June 27, 2016. Ethiopia is a country in the Horn of Africa with nine regional states (Afar, Amhara, Benishangul-Gumuz, Gambella, Harari, Oromia, Somali, Southern Nations, Nationalities, and People's Region (SNNP) and Tigray) and two city administrations (Addis Ababa and Dire Dawa). It has a population of 114 million. Of which, Children under age 15 (47\%) and individuals aged 15-64 (48\%) each represent nearly half of the population. Ethiopia's population is young, which is typical of countries with low life expectancies and high fertility rates $(20,21)$.

\section{Study population and sampling procedure}

All men aged 15-59 years were included in the study. The 2016 EDHS sample was stratified and selected in two stages. In the first stage, a total of 645 Enumeration Areas (EAs) (202 in urban areas and 443 in rural areas) were selected with probability proportional to EA size and with independent selection in each sampling stratum. In the second stage of selection, a fixed number of 28 households per cluster were selected with an equal probability systematic selection from the newly created household listing. For this study men data set was used and extracted the outcome and explanatory variables. Latitude and longitude coordinates were also taken from selected enumeration areas (clusters). The detailed sampling procedure was presented in the full 2016 EDHS report (20). 


\section{Data collection procedure and variables}

The study was conducted based on EDHSs data's by accessing from the DHS program official database www.measuredhs.com, after permission was granted through online request by explaining the objective of our study. The outcome variables with important predictors were extracted from Ethiopia Demographic and Health Surveys men's data set. Data were extracted using STATA version 14.0.

Risky health behaviour among men aged 15-59 were used as a dependent variable. Risky health behaviour among men aged 15-59 were used as a dependent variable. Risky health behaviour (2 items): regular alcohol use (one or more drinks per week in the last 12 months) and/or regular tobacco use (used chewing tobacco every day or smoked cigarettes every day in the last 30 days) (22). Risky health behaviour defined as those that potentially expose people to harm, or significant risk of harm, which prevent them from reaching their potential in life and which can cause significant morbidity or mortality (23).

The independent variables were level of education, sex of the household head, residence, marital status, relationship to the household head, wealth status, region, occupation, age, religion, frequency of watching television, frequency of listening to radio and marital status.

\section{Data processing and analysis}

Descriptive and summary statistics were done using STATA version 14 software. The analysis was done using STATA 14, ArcGIS 10.3 and SaTScan 9.6 software's. The data was weighted using sampling weight, primary sampling unit, and strata before any statistical analysis to restore the representativeness of the survey, to correct difference of the sample versus the target population and probabilities of selection and to tell the STATA to take into account the sampling design when calculating standard errors to get reliable statistical estimates.

Generalized structural equation model (GSEM) was used to determine factors associated with each domain of risky health behaviour (regular alcohol drinking and tobacco smoking). Each domain of risky health behaviour was binary variable that was fitted with Bernoulli family and a logit link function.

The analysis was started with a hypothesized model in Figure 1. Modifications were taken interactively by adding a path link. At the end, an over identified model with minimum information criteria was retained. A final model was selected based on statistical significance of path coefficient, the theoretical meaningfulness of the relationship and minimum information criteria. Adjusted odds ratio (AOR) with a 95\% confidence interval $(\mathrm{Cl})$ and $p$-value $<0.05$ were declared as determinant factors of risky health behaviour.

\section{Spatial autocorrelation analysis}

Spatial autocorrelation (Global Moran's I) statistic measure was used to evaluate whether risky health behaviour was dispersed, clustered, or randomly distributed in the study area. Moran's I values close to- 1 indicated disease/event dispersed, whereas I close to +1 indicated disease/event clustered, and disease/event distributed randomly if I value was zero. A statistically significant Moran's I $(p<0.05)$ led to the rejection of the null hypothesis and indicated the presence of spatial autocorrelation. ArcGIS version 10.3 was used for doing the Moran I analysis.

\section{Spatial scan statistical analysis}

Spatial scan statistical analysis was employed to identify the geographical locations of statistically significant spatial clusters of risky health behaviour among men aged 15-59 years using Kuldorff's SaTScan version 9.6 software. Spatial scan statistic used a scanning window that moves across the study area. Scan statistics did scan gradually across the space to 
identify the number of observed and expected observations inside the window at each location. The scanning window with the maximum likelihood was the most likely high performing clusters, and a p-value was assigned to this cluster (24). The maximum cluster size was set at $50 \%$ of the population at risk. Men without risky health behaviour taken as controls and those with risky health behaviour were taken as cases represented by a 0/1 variable to fit the Bernoulli model. The number of cases in each location had Bernoulli distribution and the model required data with or without risky health behaviour. A Likelihood ratio test statistic was used to determine whether the number of observed cases within the potential cluster was significantly higher than the expected or not. Primary and secondary clusters were identified using p-values and likelihood ratio tests based on the 999 Monte Carlo replications (24).

\section{Results}

\section{Characteristics of study population}

A total of 12,688 men aged 15-59 were included in the analysis. The overall prevalence of risky health behaviour in men was $31 \%$ in one or both of the domains such as regular tobacco smoking and regular alcohol drinking. About 10,187(80.29\%) were rural dwellers and 5901 (46.51\%) had primary education. The mean age of the participants was 30.83 years ( $S D \pm 11.55$ years). The household wealth index of $34.1 \%$ of the study subjects were in the two poor wealth quintiles, $19.25 \%$ were in the middle and $46.64 \%$ were in the two upper wealth quintiles.

Table 1: 
Table 1

Socio-demographic characteristics of respondents in Ethiopia from January 18 to June 27, $2016(\mathrm{~N}=12,688)$.

\begin{tabular}{|c|c|c|}
\hline Variables & Weighted frequency & Percent \\
\hline \multicolumn{3}{|l|}{ Age } \\
\hline $15-19$ & 2572 & 20.27 \\
\hline $20-24$ & 1883 & 14.84 \\
\hline $25-29$ & 1977 & 15.58 \\
\hline $30-34$ & 1635 & 12.88 \\
\hline $35-39$ & 1385 & 10.92 \\
\hline $40-44$ & 1206 & 9.51 \\
\hline $45-49$ & 947 & 7.47 \\
\hline $50-54$ & 582 & 4.59 \\
\hline $55-59$ & 501 & 3.95 \\
\hline \multicolumn{3}{|l|}{ Residence } \\
\hline Urban & 2501 & 19.71 \\
\hline Rural & 10187 & 80.29 \\
\hline \multicolumn{3}{|l|}{ Region } \\
\hline Tigray & 795 & 6.27 \\
\hline Afar & 90 & 0.71 \\
\hline Amhara & 3230 & 25.46 \\
\hline Oromia & 4758 & 37.50 \\
\hline Somali & 329 & 2.59 \\
\hline Benishangul & 128 & 1.00 \\
\hline SNNPR & 2596 & 20.46 \\
\hline Gambela & 37 & 0.29 \\
\hline Harari & 31 & 0.25 \\
\hline Addis Ababa & 621 & 4.90 \\
\hline Dire Dawa & 73 & 0.57 \\
\hline \multicolumn{3}{|c|}{ Level of education } \\
\hline No education & 3840 & 30.26 \\
\hline Primary & 5901 & 46.51 \\
\hline Secondary & 1846 & 14.55 \\
\hline Higher & 1101 & 8.67 \\
\hline \multicolumn{3}{|l|}{ Religion } \\
\hline Others ${ }^{*}=$ Cathc & thern Nation Nationali & oples $R €$ \\
\hline
\end{tabular}




\begin{tabular}{|c|c|c|}
\hline Variables & Weighted frequency & Percent \\
\hline Orthodox & 5690 & 44.84 \\
\hline Protestant & 2748 & 21.66 \\
\hline Muslim & 3985 & 31.41 \\
\hline Other* & 265 & 2.09 \\
\hline \multicolumn{3}{|l|}{ Sex of household head } \\
\hline Male & 11122 & 87.66 \\
\hline Female & 1566 & 12.34 \\
\hline \multicolumn{3}{|l|}{ Wealth index } \\
\hline Poorest & 2009 & 15.83 \\
\hline Poorer & 2318 & 18.27 \\
\hline Middle & 2443 & 19.25 \\
\hline Richer & 2727 & 21.49 \\
\hline Richest & 3191 & 25.15 \\
\hline \multicolumn{3}{|l|}{ Marital status } \\
\hline Never married & 4895 & 38.58 \\
\hline Married/living together & 7471 & 58.88 \\
\hline Divorced/separated/widowed & 322 & 2.54 \\
\hline \multicolumn{3}{|l|}{ Currently working } \\
\hline No & 1430 & 11.27 \\
\hline Yes & 11258 & 88.73 \\
\hline
\end{tabular}

\section{Spatial Distribution Of Risky Health Behaviour}

This study revealed that the spatial distribution of risky health behaviour was found to be spatially clustered in Ethiopia with Global Moran's I $0.12(p<0.0001)$. Cluster of high rates in risky health behaviour was observed over the study area. The outputs were automatically generated keys on the right and left sides of each panel. Given the z-score of 4.02 indicated that there is less than $1 \%$ likelihood that this clustered pattern could be the result of a random chance. The bright red and blue colours to the end tails indicate an increased significance level (Fig. 2).

Figure 2: Spatial autocorrelation analysis of risky health behaviour among males in Ethiopia, 2016

Spatial clustering of risky health behaviour was found at regional levels. Of a total of 12,688 men interviewed in 2016, about 3,938 (31.04\%) had risky health behaviour. The highest risky health behaviour was spatially clustered in Tigray, Amhara, eastern part of Benishangul and Gambella regions; While Oromia and Somali regions had lowest risky health behaviour (Fig. 3). 
Figure 3: Spatial distribution of risky health behaviour among adult males across regions in Ethiopia, 2016.

Spatial SaTScan analysis of risky health behaviour (Bernoulli based model)

A total of 125 significant clusters were identified at which 118 were most likely (primary clusters) and 7 secondary clusters of risky health behaviour were identified. The primary clusters were located in Tigray, Amhara and north-eastern Benishangul regional states. The primary clusters were centred at $12.669915 \mathrm{~N}, 36.775082 \mathrm{E}$ with $313.13 \mathrm{~km}$ radius, a relative risk (RR) of 2.41 and Log-Likelihood ratio (LLR) of 524.8, at $p<0.001$.It showed that men within this area had 2.4 times higher risk for risky health behaviour than men outside the area (Table 2).

Table 2

Significant spatial clusters with high rate risky health behaviour among adult males in Ethiopia, 2016.

\begin{tabular}{|c|c|c|c|c|c|c|c|}
\hline $\begin{array}{l}\text { Clus } \\
\text { ter }\end{array}$ & Enumeration area(cluster)identified & $\begin{array}{l}\text { Coordi } \\
\text { nate } \\
\text { (radius) }\end{array}$ & $\begin{array}{l}\text { Popu } \\
\text { lation }\end{array}$ & Case & RR & LLR & $\begin{array}{l}P \\
\text { value }\end{array}$ \\
\hline \multirow[t]{3}{*}{1} & \multirow{3}{*}{$\begin{array}{l}279,292,638,640,52,296,504,312,327,612,163,322,152, \\
169,259,158,431,73,602,415,516,512,80,258,361,253, \\
541,628,386,132,382,548,167,199,515,456,425,188,615, \\
498,109,429,403,583,340,24,3,533,551,268,246,98,627, \\
559,181,255,256,120,38,528,36,584,542,78,66,156,375, \\
579,150,636,137,183,575,545,597,474,35,364,400,590, \\
244,81,494,538,206,300,184,401,424,392,136,591,176, \\
355,84,482,143,531,481,478,430,160,45,604,229,449, \\
97,237,461,94,550,351,218,200,442,479,605,350\end{array}$} & $(12.669$ & \multirow[t]{3}{*}{2599} & \multirow[t]{3}{*}{1518} & \multirow[t]{3}{*}{2.41} & \multirow[t]{3}{*}{524.8} & \multirow{3}{*}{$<.001$} \\
\hline & & $\begin{array}{l}915 \mathrm{~N} \\
36.775\end{array}$ & & & & & \\
\hline & & $\begin{array}{l}082 \text { E) / } \\
313.13 \mathrm{~km}\end{array}$ & & & & & \\
\hline \multirow[t]{3}{*}{2} & \multirow[t]{3}{*}{$106,105,221,231,549,291,469$} & $(8.211$ & \multirow[t]{3}{*}{127} & \multirow[t]{3}{*}{77} & \multirow[t]{3}{*}{1.95} & \multirow[t]{3}{*}{23.2} & \multirow{3}{*}{$\begin{array}{l}<.001 \\
0.001\end{array}$} \\
\hline & & $\begin{array}{l}902 \mathrm{~N} \\
34.451\end{array}$ & & & & & \\
\hline & & $\begin{array}{l}017 \text { E) / } \\
16.65 \text { km }\end{array}$ & & & & & \\
\hline
\end{tabular}

The bright red colour indicates that the most statistically significant spatial windows of risky health behaviour. There was high risky health behaviour within the cluster than outside the cluster (Fig. 4).

Figure 4: Primary and secondary clusters of risky health behaviour among adult males across regions in Ethiopia, 2016.

\section{Factors Associated With Risky Health Behaviour}

The final model for associated factors of risky health behaviour is shown in Fig. 5 and Table 3. This model had included ten exogenous variables (age, region, residence, educational status, frequency of listening radio, marital status, religion, occupation, wealth index and frequency of watching television) and two endogenous variables (Alcohol drinking and Tobacco smoking). All path coefficients were statistically significant at an alpha level of 0.05 . Variables, namely sex of the household head and relationship to the household head were excluded from the final model as their effects were not statistically significant at an alpha level of 0.05 . 
Table 3

Associated factors of risky health behaviour among adult males in Ethiopia, 2016

\begin{tabular}{|c|c|c|c|c|}
\hline \multirow[t]{2}{*}{ Variables } & \multicolumn{2}{|c|}{ Alcohol drinking } & \multicolumn{2}{|c|}{ Tobacco smoking } \\
\hline & AOR & $95 \% \mathrm{Cl}$ & AOR & $95 \% \mathrm{Cl}$ \\
\hline \multicolumn{5}{|l|}{ Age } \\
\hline $15-29$ & Ref & Ref & Ref & Ref \\
\hline $30-44$ & 1.42 & $(1.25,1.62)$ & 2.45 & $(2.02,2.97)$ \\
\hline $45-59$ & 1.34 & $(1.15,1.56)$ & 2.28 & $(1.81,2.87)$ \\
\hline \multicolumn{5}{|l|}{ Region } \\
\hline Tigray & Ref & Ref & Ref & Ref \\
\hline Afar & 0.18 & $(0.11,0.28)$ & 7.15 & $(3.53,14.46)$ \\
\hline Amhara & 0.51 & $(0.43,0.61)$ & 0.92 & $(0.40,2.12)$ \\
\hline Oromia & 0.58 & $(0.48,0.71)$ & 4.99 & $(2.51,9.89)$ \\
\hline Somali & 0.08 & $(0.04,0.18)$ & 17.44 & $(8.85,34.32)$ \\
\hline Benishangul & 0.92 & $(0.74,1.15)$ & 13.02 & $(6.67,25.43)$ \\
\hline SNNPR & 0.36 & $(0.29,0.44)$ & 2.81 & $(1.35,5.87)$ \\
\hline Gambela & 0.87 & $(0.69,1.09)$ & 19.23 & $(9.71,38.12)$ \\
\hline Harari & 0.18 & $(0.12,0.25)$ & 19.72 & $(9.91,39.26)$ \\
\hline Addis Ababa & 0.37 & $(0.30,0.47)$ & 10.13 & $(5.05,20.28)$ \\
\hline Dire Dawa & 0.28 & $(0.21,0.38)$ & 17.49 & $(8.85,34.54)$ \\
\hline \multicolumn{5}{|l|}{ Level of Education } \\
\hline No education & Ref & Ref & Ref & Ref \\
\hline Primary & 0.95 & $(0.83,1.09)$ & 1.35 & $(1.12,1.64)$ \\
\hline Secondary & 0.82 & $(0.68,0.98)$ & 1.47 & $(1.13,1.91)$ \\
\hline Higher & 0.83 & $(0.66,1.05)$ & 1.28 & $(0.96,1.71)$ \\
\hline \multicolumn{5}{|l|}{ Watching television } \\
\hline Not at all & Ref & Ref & Ref & Ref \\
\hline Less than once a week & 1.26 & $(1.10,1.45)$ & - & - \\
\hline At least once a week & 1.35 & $(1.15,1.59)$ & - & - \\
\hline \multicolumn{5}{|l|}{ Listening to radio } \\
\hline Not at all & Ref & Ref & Ref & Ref \\
\hline Less than once a week & 1.33 & $(1.15,1.53)$ & - & - \\
\hline At least once a week & 1.42 & $(1.25,1.62)$ & - & - \\
\hline
\end{tabular}

Others $^{*}=$ Catholic, cultural belief 


\begin{tabular}{|c|c|c|c|c|}
\hline \multirow[t]{2}{*}{ Variables } & \multicolumn{2}{|c|}{ Alcohol drinking } & \multicolumn{2}{|c|}{ Tobacco smoking } \\
\hline & AOR & $95 \% \mathrm{Cl}$ & AOR & $95 \% \mathrm{Cl}$ \\
\hline \multicolumn{5}{|l|}{ Marital status } \\
\hline Never married & Ref & Ref & Ref & Ref \\
\hline Married/living together & 1.33 & $(1.15,1.54)$ & 1.94 & $(1.54,2.44)$ \\
\hline Divorced/separated/widowed & 1.79 & $(1.34,2.39)$ & 3.63 & $(2.49,5.28)$ \\
\hline \multicolumn{5}{|l|}{ Religion } \\
\hline Orthodox & Ref & Ref & Ref & Ref \\
\hline Protestant & 0.12 & $(0.09,0.14)$ & 0.82 & $(0.60,1.11)$ \\
\hline Muslim & 0.04 & $(0.03,0.05)$ & 1.84 & $(1.48,2.29)$ \\
\hline Other & 0.40 & $(0.29,0.55)$ & 1.96 & $(1.23,3.16)$ \\
\hline \multicolumn{5}{|l|}{ Occupation } \\
\hline Not working & Ref & Ref & Ref & Ref \\
\hline Professional & 2.51 & $(1.87,3.36)$ & - & - \\
\hline Clerical & 3.03 & $(1.91,4.82)$ & - & - \\
\hline Sales & 3.12 & $(2.36,4.12)$ & - & - \\
\hline Agricultural & 2.68 & $(2.14,3.36)$ & - & - \\
\hline Services & 2.32 & $(1.63,3.29)$ & - & - \\
\hline Skilled manual & 3.47 & $(2.70,4.46)$ & - & - \\
\hline Unskilled manual & 3.05 & $(2.15,4.32)$ & - & - \\
\hline Others & 2.69 & $(2.04,3.56)$ & - & - \\
\hline \multicolumn{5}{|l|}{ Wealth status } \\
\hline Poor & Ref & Ref & Ref & Ref \\
\hline Middle & - & - & 0.85 & $(0.67,1.09)$ \\
\hline Rich & - & - & 0.50 & $(0.41,0.61)$ \\
\hline \multicolumn{5}{|l|}{ Residence } \\
\hline Urban & Ref & Ref & Ref & Ref \\
\hline Rural & 1.36 & $(1.13,1.64)$ & - & - \\
\hline
\end{tabular}

Men aged 30-44 and 45-59 years had the highest probability of smoking tobacco compared to those aged 15-29 [(AOR = $2.45,95 \% \mathrm{Cl}=2.02-2.97),(\mathrm{AOR}=2.28,95 \% \mathrm{Cl}=1.81-2.87)]$ respectively. The odds of drinking alcohol among men aged $30-44$ and $45-59$ years was increased by $58 \%$ and $66 \%$ as compared with those aged $15-29$.

The odds of drinking alcohol were decreased in Afar, Amhara, Oromia, Somali, SNNPR, Harari, Addis Ababa and Dire Dawa as compared with Tigray. However, the probability of smoking tobacco was increased in Afar, Oromia, Somali, Benishangul, SNNPR, Gambela, Harari, Addis Ababa and Dire Dawa as compared with Tigray. 
The odds of drinking alcohol were decreased by $18 \%$ among those who completed secondary education as compared with those with no education. The likelihood of smoking tobacco was increased by $35 \%$ and $47 \%$ among those who completed primary and secondary education respectively as compared with those with no education.

The likelihood of drinking alcohol was increased by $26 \%$ and $35 \%$ among men who were watching television less than once a week and at least once a week as compared with those were not watching television at all respectively.

The odds of drinking alcohol were increased by $33 \%$ and $42 \%$ among men who were listening to radio less than once a week and at least once a week as compared with those were not listening to radio at all respectively.

The likelihood of drinking alcohol was increased by $33 \%$ and $79 \%$ among men who were married and separated as compared with those who were never married. Being married and separated were 1.94 times and 3.63 times more likely to smoke tobacco than those who were never married.

\section{Figure 5: GSEM for associated factors of risky health behaviour among adult males in Ethiopia, 2016}

The odds of drinking alcohol were decreased by $88 \%, 96 \%$ and $60 \%$ among Protestant, Muslim and Catholic religion followers as compared with Orthodox religion followers. The likelihood of smoking tobacco was increased by $84 \%$ among men who were Muslim religion follower as compared with Orthodox religion followers.

Men with active employment were high likely to drink alcohol as compared with the unemployed. The probability of smoke tobacco decreased with wealth. The odds of smoking tobacco were decreased by $50 \%$ among those with rich wealth index than those in poor wealth index. Men in rural area were 1.36 times more likely to drink alcohol than those in urban area.

Table 3:

\section{Discussion}

Using the EDHS data and an appropriate modelling approach, this study further assessed spatial distribution and factors associated with risky health behaviour (regular alcohol drinking and/or regular tobacco smoking) among men in Ethiopia. This study revealed that the spatial distribution of risky health behaviour in Ethiopia was non-random.

A geographic difference demonstrated that risky health behaviour is a public health problem in 4 of the 11 Ethiopian states. Risky health behaviour was highly clustered in Tigray, Amhara, eastern part of Benishangul and Gambella regional state of Ethiopia. In line with this, high proportion clustering, spatial scan statistics analysis revealed that 125 significant clusters were found. The geographical difference of risky health behaviour across the regional states might be attributable to the regional variation of culture and religion, difference in climate and number of people who were unemployed in the specified regions.

According to the final model age, region, residence, educational status, frequency of listening radio, marital status, religion, occupation, wealth index and frequency of watching television were identified as associated factors of risky health behaviour in Ethiopia.

Men aged 30-44 and 45-59 years had a higher likelihood of risky health behaviour compared with men aged 15-29 years. This finding is in line with other study finding from Zambia (25), Namibia (26) and India (27). This could be due to the fact that as age increase, they can afford the cost and their job and family stress causing individual to take smoking and drinking as coping mechanism. This finding is in contrast with the study done in Burkina Faso (28).

Like previous studies $(29,30)$, in the current analysis, educated men were less likely to drink alcohol as compared to those with no education. It is true that education enhance awareness about the health effects of alcohol products. Educated men were high likely to smoke tobacco as compared to those with no education. This findings are in contrast with the finding of

Page $11 / 19$ 
the study done in Zambia (25). This could be significant number of people believe that smoking is cool, fun, fashionable and modern than drinking alcohol. This could be the reason for the discrepancy for drinking alcohol and smoking tobacco among educated men.

Men with active employment were high likely to drink alcohol as compared with the unemployed. This finding is in contrast with other study finding from France (29). This could be due to the fact that men with active employment had a higher level of socioeconomic status and low financial stress.

This study revealed there to be a significant difference in the proportion of men who drink alcohol according to place of residence (urban/rural). The likelihood of drinking alcohol was higher for rural residents compared with urban residents. This discrepancy could be due to cultural and level of exposure to alcohol is different. Furthermore, there may be social pressure to drink alcohol in rural residence.

The rich wealth index compared with poor wealth index was associated with a lower risk of smoking tobacco. Results of this study show that the odds of smoking tobacco was decreased by $50 \%$ among those with rich wealth index than those in poor wealth index; this is in line with the results of other studies conducted in other countries like Zambia (25) and India (31). This might be due to the fact that having a high income would increase responsiveness to health promotion and health information regarding risky health behaviour.

In our study religion was significantly associated with risky health behaviour. Non-Orthodox were at low risk of drinking alcohol compared with Orthodox participants. On the contrary, Non-Orthodox were at high risk of smoking tobacco compared with Orthodox participants. This could be due to non-orthodox participants located in these areas cultivates tobacco plants and prepare for local markets. The married and divorced men had a higher likelihood of risky health behaviour compared with those who have never married. This could be due to the fact that married and divorced men had emotional distress that may lead them to become smoker or drinker for comfort.

Compared with those who never watched television or listened to radio at all, those who watched television or listened to the radio at least once a week were at a higher risk of alcohol drinking. This findings are in contrast with the finding of the study done in Zambia (25). This could be the fact that those who watched television or listened to the radio exposed to alcohol industry advertisement as possible causal agents in the stimulation of demand for alcohol.

One of the strengths of this study was using a large sample size, which is representative at national and regional level, providing depths for generalization. Furthermore, this paper builds a body of knowledge on the spatial disparity of risky health behaviour and identifies hotspot areas to enhance decision making on public health problem of risky health behaviour through cluster analysis. This study is not free from limitation. It is challenge to know the exact cases' location since the location of data values was shifted 1-2 kms for urban and $5 \mathrm{kms}$ for rural areas for data confidentiality issues. Similarly, essential factors such as peer pressure to smoke or drink, factors to assess other domain of risky health behaviour like physical inactivity, unhealthy diet were not available in the EDHS so that it was not possible to incorporate these variables in the analysis. Furthermore, Alcohol and tobacco use were self-reported by the survey participants, hence there is a chance of under or over reporting.

\section{Conclusion}

This study indicates that considerable geographic disparities in risky health behaviour occur within Ethiopia. The results of this study revealed that risky health behaviour among men varied across the country; significant risky health behaviour hotspots were observed in Tigray, Amhara and north-eastern Benishangul national regional states. Residence, frequency of listening radio, occupation and frequency of watching television were significantly associated with drinking alcohol while wealth index was associated with tobacco smoking. Age, region, educational status, marital status and religion had a significant association with both domains of risky health behaviour. The national press media should involve in ban of advertising and promotion of alcohol and tobacco. Aggressive health education efforts should be directed toward this high-

Page 12/19 
risk population. Improving risky health behaviours is an important approach to reducing health disparities and for more costeffective utilization of scares resources in the public health sector.

\section{Abbreviations}

AOR

Adjusted Odds Ratio

$\mathrm{Cl}$

Confidence Interval;

COPD

Chronic Obstructive Pulmonary Disease;

COR

Crude odds ratio;

CSA

Central Statistics Agency;

EA

Enumeration Area;

EDHS

Ethiopian Demographic and Health Survey;

GSEM

Generalized Structural Equation Model;

SD

Standard Deviation;

SDG

Sustainable Development Goal;

SNNPR

Southern Nation and Nationality and Peoples Region;

WHO

World Health Organization

\section{Declarations}

\section{Ethics approval and consent to participate}

The study doesn't involve the collection of information from subjects. Consent to participate is not applicable. We sent a onepage proposal abstract of the study to the DHS program office. They gave permission to access the data with reference number of 144751.

\section{Consent for publication}

Not applicable

\section{Availability of data and materials}

All necessary information's were included with in the manuscript

\section{Competing interests}


The authors declare that they have no competing interests.

\section{Funding}

The authors receive no funding for this study

\section{Authors' Contributions}

Conception of the work, design of the work, acquisition of data, analysis and interpretation of data was done by SA. Data curation, drafting the article, revising it critically for intellectual content, validation and final approval of the version to be published was done by $\mathrm{SA}, \mathrm{AB}$ and BS. All authors read and approved the final manuscript.

\section{Acknowledgments}

We would like to thank the measure DHS for providing us the data and shape files for the study area.

\section{References}

1. Steptoe A, Wardle J. Health-related Behaviour: Prevalence and Links with Disease. 2004.

2. World Health Organization. Difference between risk, risk factors, risk behaviours, risk conditions and at risk. [cited 2020 July 10]. Available from: https:// https://apps.who.int/adolescent/second-decade/section/section_5/level5_5.

3. Sussman MP, Jones SE, Wilson TW, Kann L. The youth risk behavior surveillance system: updating policy and program applications. J Sch Health. 2002;72(1):13-7.

4. World Health Organization. Noncommunicable diseases country profiles 2018. 2018.

5. [cited 2020 August 1]. Available from: https://www.who.int/publications/i/item/9789241514620.

6. World Health Organization. Global status report on alcohol and health 2018: Executive summary. World Health Organization. 2018. [cited 2020 August 2]. Available from: https://www.who.int/publications-detail-redirect/globalstatus-report-on-alcohol-and-health-2018.

7. World Health Organization. Tobacco use. 2020. [cited 2020 June 25]. Available from: https://www.who.int/newsroom/fact-sheets/detail/tobacco.

8. World Health Organization. Non communicable disease. 2018. [cited 2020 July 27]. Available from:https://www.who.int/news-room/fact-sheets/detail/noncommunicable-diseases.

9. World Health Organization. Tobacco control for sustainable development. 2017. [cited 2020 June 26]. Available from: https://www.euro.who.int/en/health-topics/disease-prevention/tobacco/publications/2017/tobacco-control-and-thesustainable-development-goals.

10. Ray R, Anish P. Global strategy to reduce the harmful use of alcohol. Indian J Med Res. 2012;135(2):261.

11. Reitsma MB, Fullman N, Ng M, Salama JS, Abajobir A, Abate KH, et al. Smoking prevalence and attributable disease burden in 195 countries and territories, 1990-2015: a systematic analysis from the Global Burden of Disease Study 2015. The Lancet. 2017;389(10082):1885-906.

12. Commar A, Vinayak P, d'Espaignet ET, Wolfenden L. WHO global report on trends in prevalence of tobacco smoking 2000-2025. WHO global report on trends in prevalence of tobacco smoking 2000-2025. 2018(Ed. 2).

13. Magitta N. Epidemiology of tobacco use and dependence in Sub-Saharan Africa: A systematic review. J Pulmonol Clin Res. 2018;2(1):9-15.

14. Shield K, Manthey J, Rylett M, Probst C, Wettlaufer A, Parry CD, et al. National, regional, and global burdens of disease from 2000 to 2016 attributable to alcohol use: a comparative risk assessment study. The Lancet Public Health. 2020;5(1):e51-61. 
15. EPHI F. WHO. Ethiopia STEPS report on risk factors for non-communicable disease and prevalence of selected NCDs. Addis Ababa: Ethiopian Public Health Institute; 2016.

16. American Cancer Society WLF. The tobacco atlas. 2015.

17. Yismaw S, Kebede H. Prevalence and Associated Factors of Alcohol Consumption Among College Students in Gondar Town, Northwest Ethiopia. Science Journal of Public Health. 2015;3(4):453-9.

18. Alebachew W, Semahegn A, Ali T, Mekonnen H. Prevalence, associated factors and consequences of substance use among health and medical science students of Haramaya University, eastern Ethiopia, 2018: a cross-sectional study. BMC Psychiatry. 2019;19(1):343.

19. Duko B, Melese Y, Ebrahim J. Determinants of cigarette smoking among adolescents in Ethiopia: A cross-sectional study. Tobacco induced diseases. 2019;17.

20. Lodebo T, Hajito K, Gebrehiwot T, Achicha T. Prevalence of cigarette smoking and its associated factors among parents at Misrak Bedawacho District, Southern Ethiopia. J Addiction Prevention. 2017;5(1):9.

21. CSACE I. Ethiopia demographic and health survey 2016. Ethiopia: CSA and ICF.: Addis Ababa; 2016.

22. Nations U. Countries in the world by population (2020). Worldometer. 2020.

23. Multiple Threats: The Co-Occurence of Teen Health Risk Behaviors - Scientific Figure on ResearchGate. Available from: https://www.researchgate.net/figure/Definitions-of-Health-Risk-Behaviors-as-Measured-in-Add-Health_tbl1_255624525 [accessed $29 \mathrm{Jul}, 2020]$.

24. Igra V, Irwin CE. Theories of adolescent risk-taking behavior. Handbook of adolescent health risk behavior: Springer; 1996. p. 35-51.

25. Kulldorff M. SaTScanTM user guide. Boston[Google Scholar]. 2006.

26. Nyirenda HT, Mulenga D, Silitongo M, Nyirenda HB, Nyirenda T. Spatial distribution and correlates of smoking in Zambia. BMJ open. 2019;9(8):e030044.

27. He Z, Bishwajit G, Yaya S. Prevalence of alcohol and tobacco use among men and women in Namibia. International Journal of Environmental Research Public Health. 2019;16(1):59.

28. Ganesh Kumar S, Premarajan K, Subitha L, Suguna E, Vinayagamoorthy VK. Prevalence and pattern of alcohol consumption using alcohol use disorders identification test (AUDIT) in rural Tamil Nadu, India. Journal of clinical diagnostic research: JCDR. 2013;7(8):1637.

29. Bonnechère $B$, Cissé $K$, Millogo T, Ouédraogo GH, Garanet $F$, Ouedraogo MA, et al. Tobacco use and associated risk factors in Burkina Faso: results from a population-based cross-sectional survey. BMC Public Health. 2019;19(1):1466.

30. Auguste A, Dugas J, Menvielle G, Barul C, Richard J-B, Luce D. Social distribution of tobacco smoking, alcohol drinking and obesity in the French West Indies. BMC Public Health. 2019;19(1):1424.

31. Kumar A, editor Spatial pattern of risky health behavior in India: evidence from recent National Family Health Survey 2015-16. TOBACCO INDUCED DISEASES; 2018: EUROPEAN PUBLISHING SCIENCE \& TECHNOLGY PARK CRETE,(STEPC), N PLASTIRA $100 \& \# 8230$.

32. Subramanian S, Nandy S, Kelly M, Gordon D, Smith GD. Patterns and distribution of tobacco consumption in India: cross sectional multilevel evidence from the 1998-9 national family health survey. Bmj. 2004;328(7443):801-6.

\section{Figures}




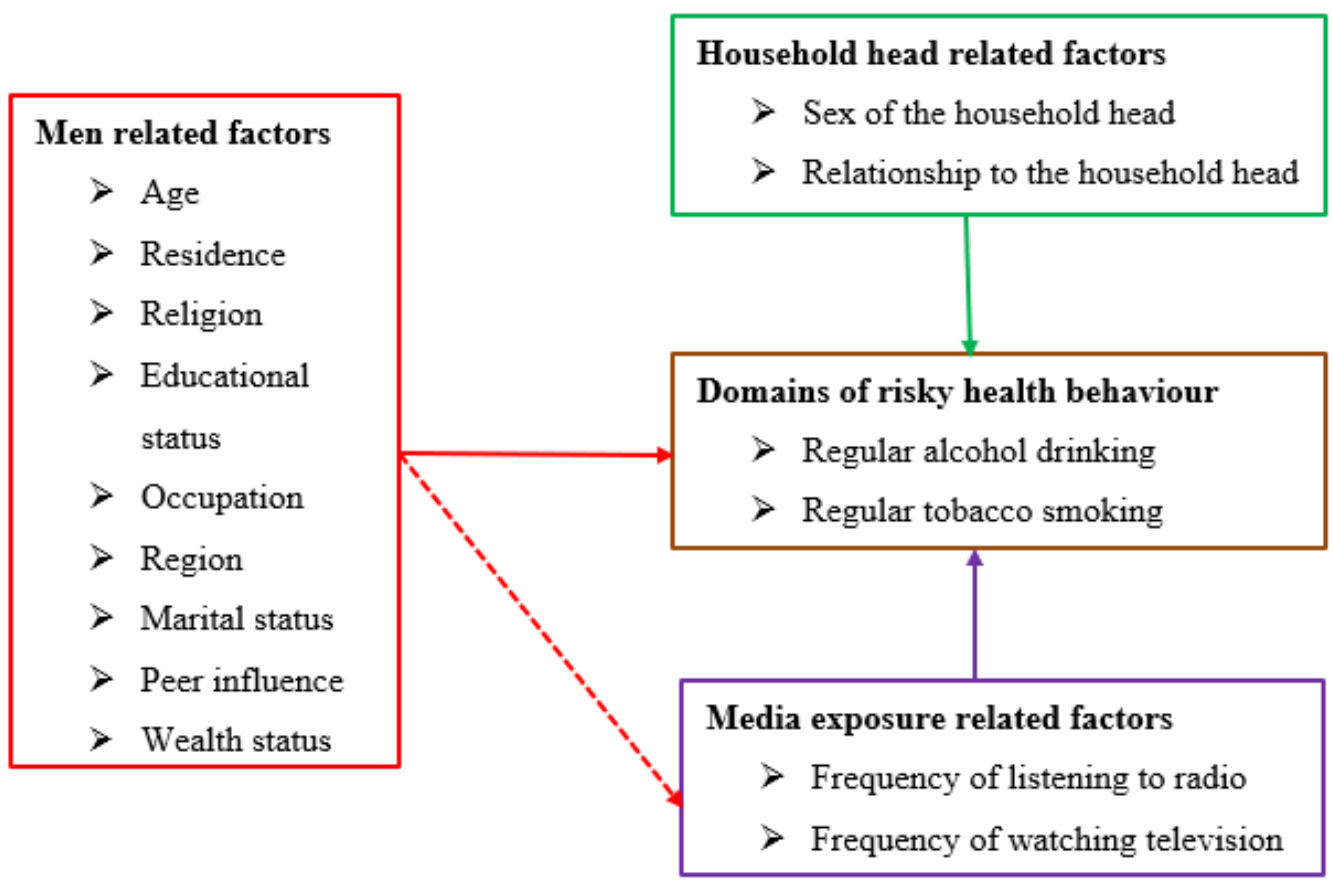

Figure 1

Hypothesized model for factors associated with risky health behaviour among males in Ethiopia.

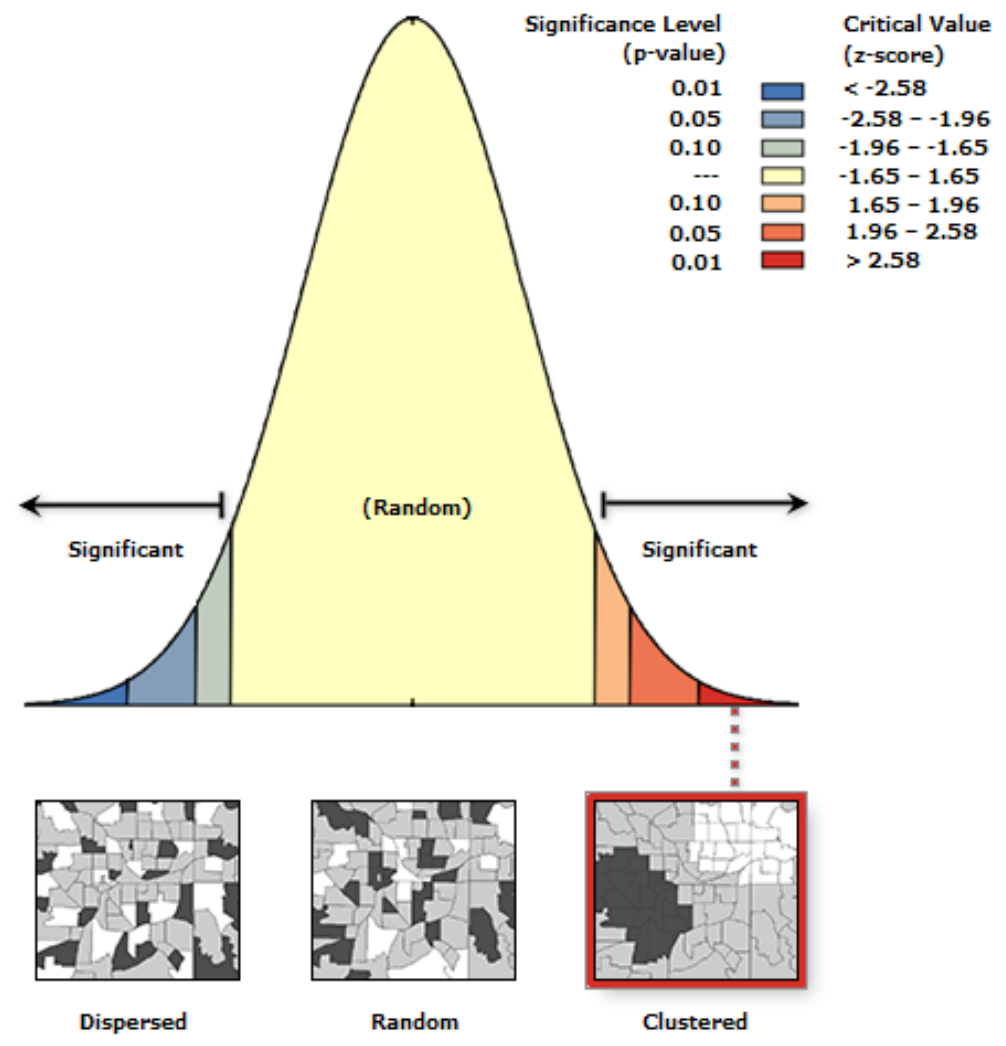

Figure 2

Spatial autocorrelation analysis of risky health behaviour among males in Ethiopia, 2016 


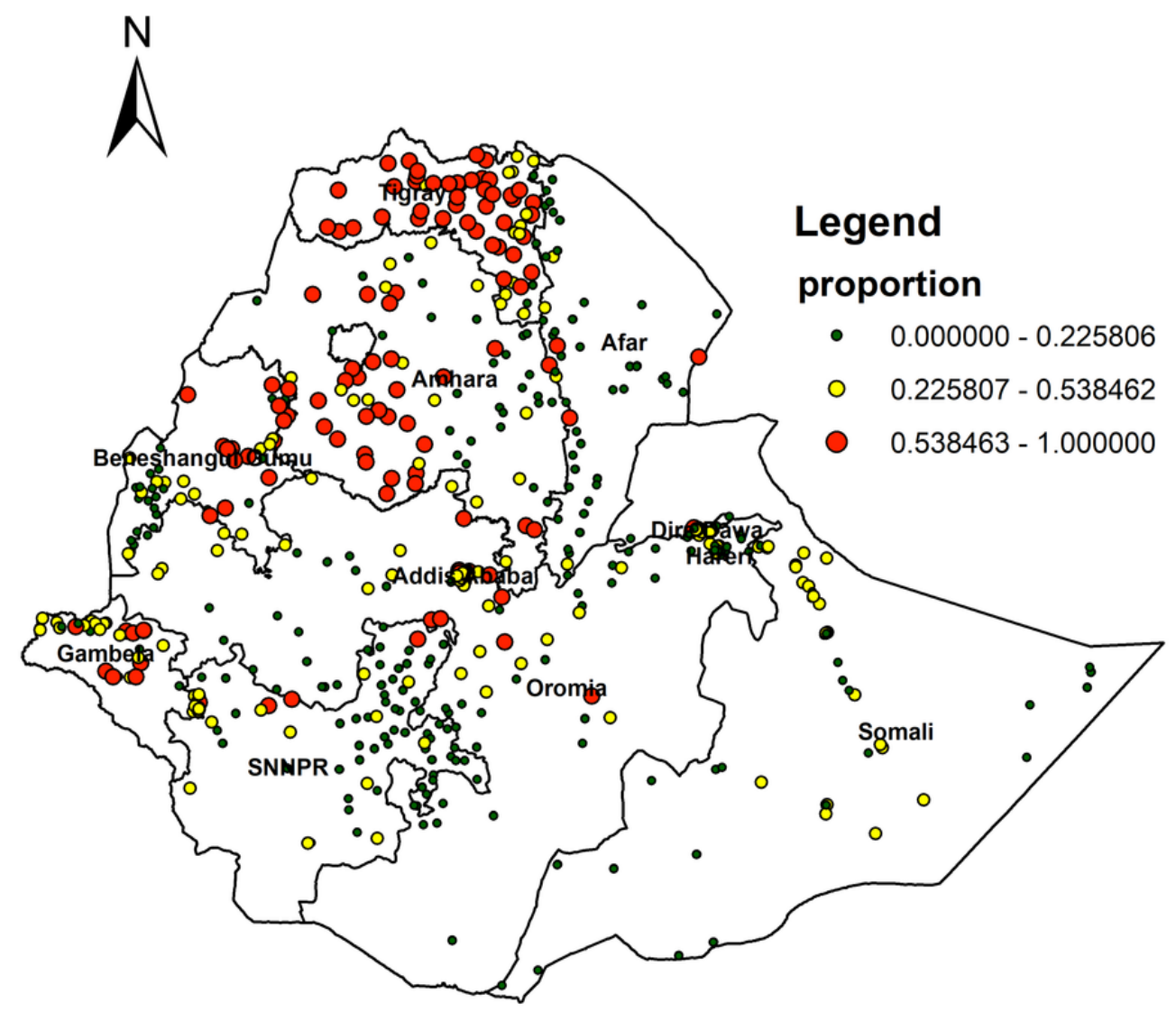

Source:Shape file from CSA in Ethiopia,2013

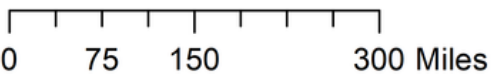

Figure 3

Spatial distribution of risky health behaviour among adult males across regions in Ethiopia, 2016. 


\section{Spatial scan statistics of risky health behavior in Ethiopia,2016}

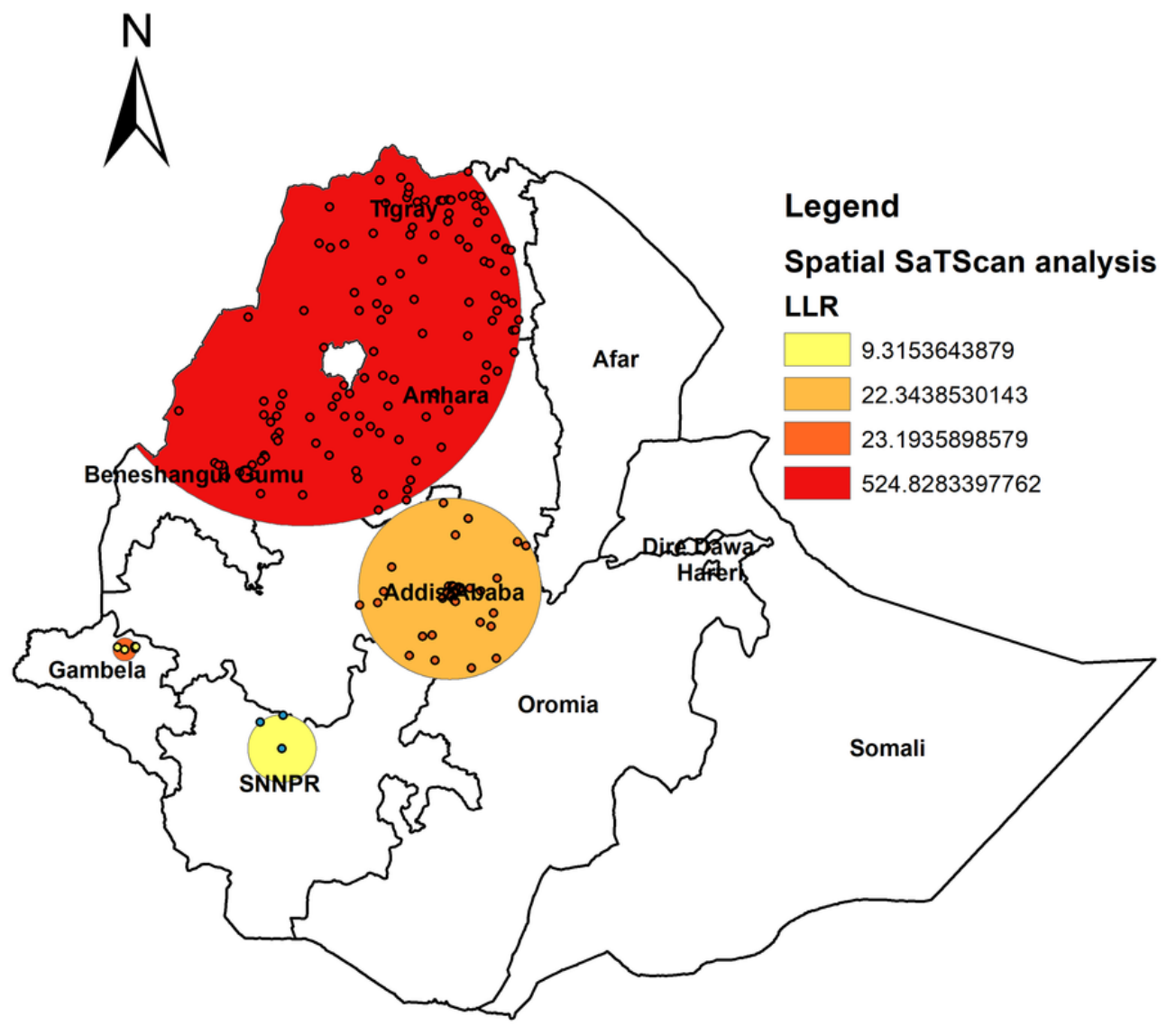

Source:Shape file from CSA in Ethiopia,2013

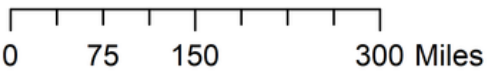

Figure 4

Primary and secondary clusters of risky health behaviour among adult males across regions in Ethiopia, 2016. 


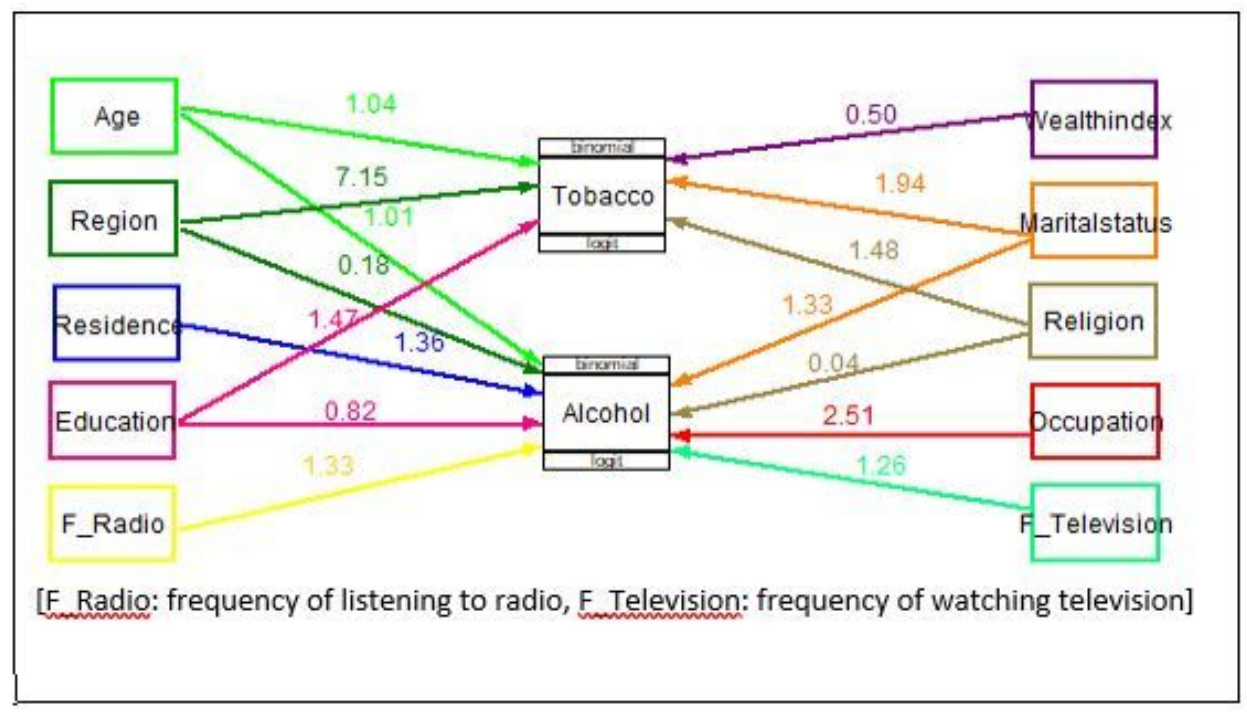

\section{Figure 5}

GSEM for associated factors of risky health behaviour among adult males in Ethiopia, 2016 